\title{
Efficiency of antiviral treatment in COVID-19
}

\author{
NICOLETA NEGRUT $^{1 *}$, ADRIANA CODREAN $^{1 *}$, IOANA HODISAN $^{2}$, \\ SIMONA BUNGAU ${ }^{3 *}$, DELIA MIRELA TIT ${ }^{3}$, RUXANDRA MARIN ${ }^{3 *}$, TAPAN BEHL ${ }^{4}$, \\ FLORIN BANICA $^{3}$, CAMELIA C. DIACONU ${ }^{5}$ and DELIA CARMEN NISTOR-CSEPPENTO ${ }^{1}$
}

\author{
${ }^{1}$ Department of Psycho-Neuroscience and Recovery, Faculty of Medicine and Pharmacy, University of Oradea, \\ 410073 Oradea; ${ }^{2}$ Department of infectious Diseases, 'Gavril Curteanu' Municipal Hospital Oradea, 410469 Oradea; \\ ${ }^{3}$ Department of Pharmacy, Faculty of Medicine and Pharmacy, University of Oradea, 410028 Oradea, Romania; \\ ${ }^{4}$ Chitkara College of Pharmacy, Chitkara University, 140401 Punjab, India; ${ }^{5}$ Department 5, 'Carol Davila' \\ University of Medicine and Pharmacy, 050474 Bucharest, Romania
}

Received March 1, 2021; Accepted March 31, 2021

DOI: $10.3892 / \mathrm{etm} .2021 .10080$

\begin{abstract}
The severe acute respiratory syndrome coronavirus 2 (SARS-CoV-2) pandemic is responsible for generating a global effort to discover urgent therapeutic solutions to limit the human damage caused by COVID-19. In the period of April to June 2020, 105 patients diagnosed with COVID-19 met the conditions for inclusion in the present study. They were treated with antiviral therapy according to local guidelines: D group (53 cases), treated with darunavir/ritonavir (DRV/r); and K group (52 cases), treated with lopinavir/ritonavir (LPV/r). Patients from the $\mathrm{K}$ group required 7.5 days of hospitalization less compared to those from the D group $(\mathrm{P}<0.001)$. The blood oxygen saturation values recorded in the groups were statistically different [K group $(94.02 \pm 3.12 \%)$ vs. $\mathrm{D}$ group $(92.13 \pm 4.24 \%), \mathrm{P}=0.010]$. The percentage of patients with unsatisfactory clinical evolution were non-significantly higher in the D group compared with the K group [20 (37.74\%) vs. $12(23.08 \%), \mathrm{P}=0.157]$. We did not note statistically significant differences between the two groups tracked considering the values for the Brescia-COVID Respiratory Severity Scale (BCRSS) of the patients with unsatisfactory clinical evolution, nor of the chest $\mathrm{CT}^{\prime}$ evolution after 10 days of therapy. We did not register significant adverse effects after antiviral therapy in the two groups. Antiviral therapy with LPV/r had some favorable results compared to DRV/r in patients with COVID-19. Both therapies were well tolerated.
\end{abstract}

Correspondence to: Professor Delia Mirela Tit or Dr Florin Banica, Department of Pharmacy, Faculty of Medicine and Pharmacy, University of Oradea, 29 N. Jiga Street, 410028 Oradea, Romania

E-mail:mirela_tit@yahoo.com

E-mail: florinbanica1@gmail.com

*Contributed equally

Key words: SARS-CoV-2, COVID-19, Kaletra, lopinavir, darunavir

\section{Introduction}

Coronaviruses are an ancient group of viruses so named after a crown-like spike which decorates their surface, able to cross the species barrier. Common human coronaviruses (229E, NL63, OC43, HKU1) are responsible for the flu-like syndrome, and only in rare cases induce lower respiratory tract manifestations. Subtypes that have crossed the species barrier have been shown to be responsible for severe forms of the diseases in humans (1).

The best-known viruses that can make this leap include Middle East respiratory syndrome coronavirus (MERS-CoV), severe acute respiratory syndrome coronavirus (SARS-CoV), and more recently severe acute respiratory syndrome coronavirus 2 (SARS-CoV-2). SARS-CoV-2 is responsible for the pandemic that started on March 2020. The clinical scenario is variable and individualized. Clinical manifestations are found in about half of the cases as flu-like syndromes, and only $10-15 \%$ from them evolve into life-threatening complications such as acute pneumonia, acute respiratory distress syndrome, disseminated intravascular coagulation, and even death $(2,3)$. Although the case fatality rate $(2.29 \%)$ (4) remains much lower compared to MERS-CoV (37.1\%) (5) and SARS-CoV (9.6\%) (6), COVID-19 is still an unsolved issue because of the mortality rate which ranges proportional to age (4), and the high rate of transmission of the virus (7).

Antiviral treatment for COVID-19 is still a challenge. To date, studies have not been able to identify a sufficiently potent antiviral drug for infections with SARS-CoV-2. Yet, several molecules have been studied to identify effective treatment.

Hydroxychloroquine has been approved for the treatment of malaria and autoimmune diseases, with an antiviral effect by inhibiting fusion of the virus with the cellular membrane of the host, by blocking the release of the viral genome and by immunomodulatory effects. Yet, results regarding its effectiveness for COVID-19 are contradictory until now (8-10). Hydroxychloroquine combined with azithromycin has also been proposed for the treatment of COVID-19. This combination has antiviral effects by decreasing viral replication (via interferon), by decreasing the effect of inflammatory 
cytokines and stimulating neutrophil activation. Also, the effect of hydroxychloroquine is reinforced by the presence of the antibiotic. The combination of the two has been intensively studied, but the results are contradictory to date (8).

HIV protease inhibitors [lopinavir (LPV) with ritonavir (r), and darunavir (DRV) with cobicistat (c) or ritonavir (r)] used until now in the treatment of HIV infection has also attracted the attention of the international medical community as possible potent drugs in the fight against SARS-CoV-2. Their effect could be mediated by inhibiting the viral 3-chymotrypsin-like protease, necessary for viral replication. So far, the DRV/r and LPV/r combinations have been shown to have the same mechanism for inhibiting the HIV replication, but DRV/r appears to be more effective and with fewer adverse effects (11). Starting from these premises, the present study aimed to investigate the effect of these drugs on SARS-CoV-2 infection. To date, there are 2 therapeutic trials that use DRV/r as a treatment for COVID-19 (ClinicalTrials.gov Identifier: NCT04252274; NCT04425382) and 42 that use LPV/r (12). Although some studies support the ineffectiveness of HIV protease inhibitor treatment, many studies are still ongoing, thus the conclusions are still distant (13-15).

Remdesivir is a nucleotide analogue with favorable results in the case of COVID-19, by inhibiting viral replication (16). The drug was recently approved by the US Food and Drug Administration for use in severe forms of infection (17). Although the drug has the most promising results among the molecules investigated for SARS-CoV-2 infection, the high price and limited access for most patients make it practically unusable at this moment on a large scale (16).

Therapeutic options for patients with COVID-19 are limited, expensive, and with molecules whose efficacy is contradictory in current studies.

The geographical area of Romania, southeastern Europe, is characterized by various infectious pathologies (18-20). In a field often exposed to infectious agents, the current pandemic with COVID-19 was initially associated with a lower severity compared to other parts of the world. The therapeutic approach of the present study, in this context, was made considering the particularities of our geographical area.

Based on the data available to date and considering the fact that the combinations of LPV/r and DRV/r have the same mechanism of action, this study aimed to evaluate the efficacy of the two combinations in COVID-19 patients with moderate form of the disease.

\section{Patients and methods}

Protocol. A 3-month retrospective study from April 1, 2020, until June 30, 2020 was conducted at the Department of Infectious Disease, Municipal Hospital Oradea 'Gavril Curteanu', Oradea, Bihor County, Romania. All adult patients, diagnosed with COVID-19 with imaging of pulmonary infiltrates on chest computed tomography (CT), and who had no history of previous antiretroviral therapy were included in the study. The diagnosis and the therapy were based on the guidance of the World Health Organization (21), diagnosis and treatment guidelines for COVID-19 and local hospital guide $(7,22)$. Confirmation of COVID-19 was performed using a single positive test which highlighted the RNA of the virus in the upper respiratory tract specimens (nasopharyngeal and oropharyngeal) using real-time polymerase chain reaction (qPCR) assay.

Patients included in the study were treated with lopinavir/ritonavir (LPV/r) [Kaletra (K)] (200/50 mg) (2 tablets $\mathrm{q} 12 \mathrm{~h}$ ) for 10 or 14 days ( $\mathrm{K}$ group), or darunavir/ritonavir (DRV/r); 800 mg DRV (1 tablet qDay) plus ritonavir $100 \mathrm{mg}$ (1 tablet qDay) for 10 or 14 days (D group). All treatment regimens had associated Plaquenil, antibiotic and anticoagulant. The duration of antiviral therapy was a maximum of 14 days (optionally 10 if patients had 2 consecutive negative qPCR tests at 24-h intervals, at 10 day checks). Patients were discharged after two consecutive negative qPCR tests, collected at 24-h intervals.

The demographic data (age, sex, residence), past medical history [obesity, cardiovascular disease comorbidities (CVC), chronic pulmonary diseases (CPD), digestive comorbidities (DC), diabetes mellitus (DM), neoplasm (N), chronic kidney disease (CKD)], toxic abuse (smoker), clinical manifestations (stomatitis, abdominal pain, nausea, vomiting, diarrhea, tachycardia), values for complete blood count and liver function tests (transaminase), qPCR test results of nasal or pharyngeal exudate, imaging aspects on chest-CT, and length of hospital admission (LHA) (calculated from the first positive qPCR test to discharge), period from onset to hospitalization (POH), and Brescia-COVID Respiratory Severity Scale (BCRSS) for all patients included in the study were collected and subsequently analyzed. BCRSS was applied for the first time in Italy, for patients with COVID-19 and pneumonia, and aims to assess the clinical severity of each patient admitted to the hospital (23). Dyspnea, tachypnoea, chest imaging and oxygen saturation levels $\left(\mathrm{SpO}_{2}\right)$ /partial pressure of arterial oxygen $\left(\mathrm{PaO}_{2}\right)$, Horowitz Index for Lung Function $\left[\mathrm{PaO}_{2} /\right.$ fraction of inspired oxygen $\left(\mathrm{FiO}_{2}\right)$ ratio], non-invasive or invasive ventilation are parameters used for the scoring. Score values can range from 0 to 8 , directly proportional to the severity of the case (24). Unsatisfactory clinical evolution was considered if patients had a decrease in oxygen saturation, and $\mathrm{PaO}_{2} / \mathrm{FiO}_{2}$ ratio $<300$. BCRSS was calculated at the admission to the hospital for all cases and was repeated at the moment when unsatisfactory clinical evolution was suspected. Liver injury was considered in the case of alanine aminotransferase (ALAT) level elevated more than three times above the upper limit of normal. Patients with HIV infection, chronic liver diseases, dermatological diseases, inflammatory bowel diseases, with diarrhea or stomatitis, those previously treated with antiretroviral therapy, re-admitted for COVID-19, treated $<10$ days previously with antivirals, or received dual treatment with LPV and DRV, or BCRSS at admission to the hospital $>3$, were excluded from the study.

All patients signed an informed consent at admission in the hospital and before the start of the antiviral treatment. The study was approved by the Ethics Commission of Medicine and Pharmacy Faculty, University of Oradea (no. 5/09.21.2020) and followed the World Medical Association Code of Ethics (Declaration of Helsinki, 1967).

Diagnosis of CDI. All patients were tested according to World Health Organization (WHO) recommendations by the qPCR assay (25). The test available in our clinic, during the time 
Table I. Baseline characteristics of the patients with COVID-19.

\begin{tabular}{|c|c|c|c|}
\hline Parameter & Group K & Group D & P-value \\
\hline \multicolumn{4}{|l|}{ DD } \\
\hline Age, years, mean \pm SD & $36.45 \pm 14.99$ & $36.73 \pm 13.80$ & $0.922^{\mathrm{a}}$ \\
\hline Female, n (\%) & $35(67.30 \%)$ & $26(49.05 \%)$ & $0.058^{\mathrm{b}}$ \\
\hline Rural area, n (\%) & $26(50 \%)$ & $31(58.49 \%)$ & $0.383^{\mathrm{b}}$ \\
\hline $\mathrm{SpO}_{2}$, mean $\pm \mathrm{SD}$ & $95.29 \pm 1.97$ & $95.27 \pm 2.21$ & $0.952^{\mathrm{a}}$ \\
\hline Smoker, N (\%) & $18(34.61 \%)$ & $15(28.30 \%)$ & $0.486^{\mathrm{b}}$ \\
\hline $\mathrm{POH}$, mean $\pm \mathrm{SD}$ & $3.31 \pm 1.05$ & $3.27 \pm 1.03$ & $0.828^{\mathrm{a}}$ \\
\hline \multicolumn{4}{|l|}{$\mathrm{PMH}, \mathrm{n}(\%)$} \\
\hline Obesity & $14(26.92 \%)$ & $10(18.86 \%)$ & $0.326^{\mathrm{b}}$ \\
\hline CVC & $16(30.76 \%)$ & $21(39.62 \%)$ & $0.342^{\mathrm{b}}$ \\
\hline CPD & $9(17.30 \%)$ & $7(13.20 \%)$ & $0.559^{\mathrm{b}}$ \\
\hline $\mathrm{DC}$ & $9(17.30 \%)$ & $12(22.64 \%)$ & $0.495^{\mathrm{b}}$ \\
\hline $\mathrm{DM}$ & $8(15.38 \%)$ & $6(11.32 \%)$ & $0.540^{\mathrm{b}}$ \\
\hline $\mathrm{N}$ & $5(9.61 \%)$ & $7(13.20 \%)$ & $0.563^{\mathrm{b}}$ \\
\hline CKD & $18(34.61 \%)$ & $15(28.30 \%)$ & $0.387^{\mathrm{b}}$ \\
\hline \multicolumn{4}{|c|}{ Clinical manifestations, $\mathrm{n}(\%)$} \\
\hline Stomatitis & $0(0 \%)$ & $1(0.01 \%)$ & $0.320^{\mathrm{b}}$ \\
\hline Diarrhea & $3(0.05 \%)$ & $4(0.07 \%)$ & $0.715^{\mathrm{b}}$ \\
\hline Tachycardia & $2(0.03 \%)$ & $1(0.01 \%)$ & $0.481^{\mathrm{b}}$ \\
\hline Abdominal pain & $4(7.69 \%)$ & $6(11.32 \%)$ & $0.527^{\mathrm{b}}$ \\
\hline Nausea & $6(11.54 \%)$ & $2(3.77 \%)$ & $0.157^{\mathrm{b}}$ \\
\hline Vomiting & $3(5.77 \%)$ & $0(0.00 \%)$ & $0.083^{\mathrm{b}}$ \\
\hline \multicolumn{4}{|l|}{$\mathrm{CBC}$, mean $\pm \mathrm{SD}$} \\
\hline $\mathrm{WBC}\left(\mathrm{x} 10^{3} / \mathrm{mm}^{3}\right)$ & $9.74 \pm 2.42$ & $10.79 \pm 3.67$ & $0.084^{\mathrm{a}}$ \\
\hline $\mathrm{RBC}\left(\mathrm{x} 10^{6} / \mathrm{mm}^{3}\right)$ & $4.30 \pm 0.84$ & $4.18 \pm 0.90$ & $0.506^{\mathrm{a}}$ \\
\hline $\operatorname{PLT}\left(\mathrm{x} 10^{5} / \mathrm{mm}^{3}\right)$ & $3.63 \pm 1.34$ & $4.04 \pm 1.15$ & $0.096^{\mathrm{a}}$ \\
\hline \multicolumn{4}{|l|}{$\mathrm{LFT}$, mean $\pm \mathrm{SD}$} \\
\hline ALAT (mg\%) & $32.87 \pm 15.34$ & $27.92 \pm 16.99$ & $0.120^{\mathrm{a}}$ \\
\hline BCRSS & $0.06 \pm 0.24$ & $0.13 \pm 0.34$ & $0.196^{\mathrm{a}}$ \\
\hline
\end{tabular}

$\mathrm{DD}$, demographic data; $\mathrm{SpO}_{2}$, oxygen saturation levels; $\mathrm{POH}$, period from onset to hospitalization; $\mathrm{PMH}$, past medical history; $\mathrm{CVC}$, cardiovascular disease comorbidities; CPD, chronic pulmonary diseases; DC, digestive comorbidities; DM, diabetes mellitus; N, neoplasm; CKD, chronic kidney disease; CBC, complete blood count; WBC, white blood cells; RBC, red blood cells; PLT, platelets; LFT, liver function test, ALAT, alanine aminotransferase; BCRSS, Brescia-COVID Respiratory Severity Scale. P-value as determine by ${ }^{\mathrm{a}}$-test or ${ }^{\mathrm{b}}$ Chi-square test.

period followed was Allplex ${ }^{\mathrm{TM}}$ 2019-nCoV Assay $\left(\mathrm{CFX} 96^{\mathrm{TM}}\right.$ RT-PCR Detection Systems, Bio-Rad Laboratories, Inc.) (limit of detection 4167 copies $/ \mathrm{ml}$ ). Target genes were E gene (Sarbecovirus), RdRP gene (SARS-CoV-2) and N gene (SARS-CoV-2). The positive percent agreement of the technique was $100 \%$ (95\% CI: 92.75-100), and the negative percent agreement was $96.84 \%$ (95\% CI: 90.39-99.18) (26). If at least one target sequence of the SARS-CoV-2 viral genome was identified, then the sample was considered positive. The nasopharyngeal and oropharyngeal swabs were collected, stored and transported according to WHO recommendations (25).

$\mathrm{SpO}_{2}$ was evaluated at least twice a day, and whenever the patient's clinical condition had worsened, using a Hunan Accurate pulse oximeter. In case of a patients with a decrease in oxygen saturation, $\mathrm{PaO}_{2} / \mathrm{FiO}_{2}$ ratio was performed, using EPOC Blood Analysis System (Siemens Medical Solutions) from arterial blood. CBC determination was performed using venous blood samples collected in Tri-potassium ethylenediaminetetraacetic acid tubes. All specimens were immediately transported to the hospital laboratory. The test was performed using Beckman Coulter 628134 UniCel DxH 800 Haematology analyzer (Beckman Coulter International S.A.). Reference values were interpreted according to age and sex of the patients. To determine the blood transaminase level, the venous blood samples were collected in tubes without anticoagulant, after a fasting period, and transported immediately to the hospital laboratory. The test was performed using Beckman Coulter AU5811 Chemistry analyzer (Beckman Coulter International S.A.). The reference values were processed according to age, sex, and assay used. All patients were evaluated by chest computed tomography (CT) at admission and on day 10.

Statistical analysis. The Statistical Package for the Social Sciences (SPSS), version 26 (IBM Corp.) was used to process data and perform statistical analysis. Quantitative data are presented as means and standard deviation (SD), and qualitative data as numbers $(\mathrm{N})$ and proportions $(\%)$. The calculation 




Figure 1. Kaplan-Meier curves for the time until viral clearance occurred. LHA, length of hospital admission. D group (53 cases): Treated with darunavir/ritonavir (DRV/r); K group (52 cases): Treated with lopinavir/ritonavir (LPV/r). ${ }^{*} \mathrm{P}=0.001$, statistical significance according to log-rank test.

of the P-value was realized using Student's t-test, Chi-square test, Mann-Whitney U test, and log-rank test for Kaplan-Meier method. Statistical significance was considered for a P-value of less than 0.05 .

\section{Results}

During the study period, 205 patients with COVID-19 were diagnosed at the Department of Infectious Disease, Municipal Hospital Oradea 'Gavril Curteanu', Oradea, Bihor County, Romania. From these, only 105 met the criteria of inclusion in the study. A total of 52 patients were included in the $\mathrm{K}$ group and 53 in D group. No patient required discontinuation of antiviral therapy. The demographic characteristics of the two groups did not present statistically significantly differences (Table I).

The length of hospital admission (LHA) value was statistically significantly higher in the $\mathrm{D}$ group compared with the $\mathrm{K}$ group $(28.71 \pm 11.78$ vs. $21.25 \pm 5.99, \mathrm{P}<0.001)$. The number of patients with viral clearance differed significantly after 21 days from hospital admission [35 $(67.30 \%)$ in the K group vs. 14 (26.41\%) in the D group, $\mathrm{P}<0.001$ ) (Fig. 1).

During hospitalization, the lowest blood oxygen saturation values observed in the $\mathrm{K}$ group were statistically significantly higher compared to the D group $(94.02 \pm 3.12 \%$ vs. $92.13 \pm 4.24 \%, \mathrm{P}=0.010$ ) (Fig. 2) but the number of patients with unsatisfactory clinical evolution did not differ statistically significantly in the two groups [12 $(23.08 \%)$ in the K group vs. $20(37.74 \%)$ in the D group, $\mathrm{P}=0.157]$.

There were no statistically significant differences between the BCRSS of the patients with unsatisfactory clinical evolution for the two groups $(0.48 \pm 0.95$ in the K group vs. $0.81 \pm 1.16$ in the $\mathrm{D}$ group, $\mathrm{P}=0.111)$. For all the data we plotted the distribution by using histograms (Fig. 3).

The evolution of chest $\mathrm{CT}$ at 10 days in the $\mathrm{K}$ group improved in $69.23 \%$ patients, remained constant for $7.69 \%$, and became worse for $23.08 \%$ patients, compared to the D group where $39.62 \%$ patients had an improved evolution, $13.21 \%$ remained constant and $47.17 \%$ became worse. The results were not statistically significantly different $(\mathrm{P}=0.075)$ (Fig. 4). Stomatitis, diarrhea, abdominal pain, nausea, vomiting, tachycardia and liver injury were identified as adverse effects (AE) during the hospitalization of the patients (Table II). AE were more common in group $\mathrm{K}$ compared to group $\mathrm{D}$, but the

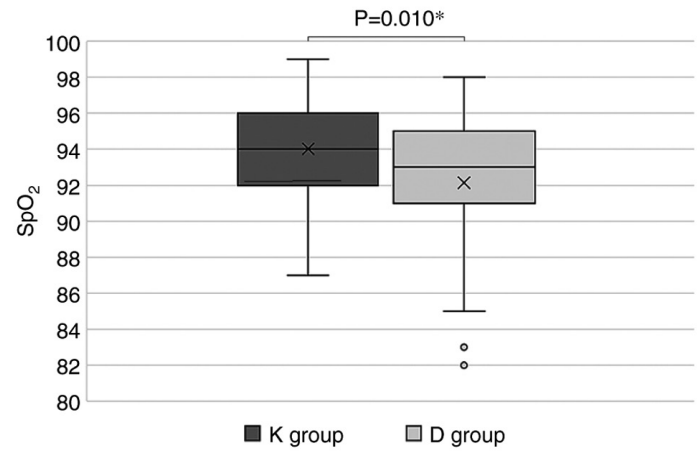

Figure 2. Histogram of the lowest $\mathrm{SpO}_{2}$ level during hospitalization. D group (53 cases): Treated with darunavir/ritonavir (DRV/r); K group (52 cases): Treated with lopinavir/ritonavir (LPV/r). " $\mathrm{P}=0.010$, statistical significance according to the Student's t-test.

difference was not statistically significant $(\mathrm{P}=0.101)$, except for diarrhea $(\mathrm{P}=0.002)$.

\section{Discussion}

Treatment for COVID-19 is still far from being standardized. Therapeutic trials conducted have not been able to present an effective antiviral drug against SARS-CoV-2, to date. To our knowledge, there is only one ongoing study in the world comparing the effectiveness of the two antivirals (LPV vs. DRV) to date (12).

The median duration of viral shedding varies depending on the form of the disease and the treatment used from 11 days for mild cases (27) to 31 days in patients with severe illness (28). In our study, patients treated with lopinavir/ritonavir (LPV/r) had a viral shedding period of 21.25 days, and those with darunavir/ritonavir (DRV/r) had 28.71 days, but the number of patients who became negative on qPCR testing was significantly different between the two groups only after day 21 of hospitalization. The results obtained by us fall within the time periods presented by the medical literature. Their importance lies in the fact that although until now it is known that the presence of viral RNA in a test is not necessarily identically with the infectivity of the case, we do not have exact data about the latter.

In this study, patients treated with $\mathrm{LPV} / \mathrm{r}$ required 7.5 days less compared to those treated with DRV/r, until viral clearance was obtained. Considering that patients were discharged at the time of obtaining viral clearance, the decrease in the hospitalization within a week leads to cost reduction and a higher turnover of patients, in the moment which the number of places available for hospitalization of COVID-19 patients is insufficient. In a study published in 2020, performed on 30 Chinese patients diagnosed with COVID-19, it was claimed that a 5-day treatment with DRV did not increase the proportion of negative test results compared to standard care alone (15). Cao et al concluded, in a study of 199 Chinese patients with SARS-Cov-2 in Wuhan, Hubei Province, China, that 10 days of LPV/r treatment did not reduce the duration of viremia detection compared to standard care alone (13).

Our study identified that in cases of COVID-19, LPV/r treatment maintained statistically significantly higher oxygen 



Figure 3. Histogram of the BCRCC. BCRSS, Brescia-COVID Respiratory Severity Scale. (A) K group (52 cases): Treated with lopinavir/ritonavir (LPV/r); (B) D group (53 cases): Treated with darunavir/ritonavir (DRV/r).



Figure 4. Evolution of chest computed tomography (CT) in patients with COVID-19 at 10 days. D group (53 cases): Treated with darunavir/ritonavir (DRV/r); K group (52 cases): Treated with lopinavir/ritonavir (LPV/r).

saturation values compared with those measured for the group with DRV/r therapy, with a difference of almost $1.89 \%$; but the number of cases that developed acute respiratory failure did not differ significantly between the two groups. Shen et al demonstrated that placing a COVID-19 patient in an nocturnal oxygen-rich environment slowed down viral replication, decreased angiotensin-converting enzyme 2 receptor expression at the target cell, improved antiviral immune response via interferons, $\mathrm{T}$ and natural killer cells, and prevented disease progression to the severe form (29).

The prompt modification of therapy according to the changes in the clinical condition of COVID-19 patients is important for the further evolution of the disease $(7,30)$. Based on relatively few elements, but specific to lung damage, the Brescia-COVID Respiratory Severity Scale (BCRSS) quickly alerts the clinician about the increasing levels of respiratory severity. The study did not identify statistically significant results for the BCRSS in the two treatment groups. The results obtained by us are in accordance with the medical literature. Thus, in the study by Cao et al, it was confirmed that LPV/r treatment in severe forms of the disease did not show obvious benefits (13).

The radiological aspect of the lung in SARS-Cov2 infection has a critical role in establishing the diagnosis and follow-up of patients. Pneumonia in cases of COVID-19 patients requires follow-up during evolution, to provide quick management in the case of aggravation (31). In our study, although treatment with LPV/r determined a satisfactory evolution of the chest $\mathrm{CT}$ in a higher percentage of patients, compared to the group treated with LPV/r, we did not register a statistically significant difference. The results obtained by us are the same as the current medical literature. Similarly, in a study by Li et al on 86 Chinese patients with mild/moderate COVID-19, the authors did not find improvement of chest CT after LPV/r treatment, compared with patients without antiviral therapy or those
Table II. Adverse effects in patients with COVID-19 during the treatment period.

\begin{tabular}{lccc}
\hline & \multicolumn{2}{c}{ Treatment groups } & \\
\cline { 2 - 3 } & $\begin{array}{c}\text { K group } \\
\text { AE, n }(\%)\end{array}$ & $\begin{array}{c}\text { D group } \\
(\mathrm{n}=52)(\%)\end{array}$ & P-value $^{\mathrm{a}}$ \\
\hline Stomatitis & $8(15.38)$ & $5(9.43)$ & 0.405 \\
Diarrhea & $22(42.31)$ & $6(11.32)$ & $\mathbf{0 . 0 0 2}$ \\
Abdominal pain & $14(26.92)$ & $7(13.21)$ & 0.126 \\
Nausea & $7(13.46)$ & $5(9.43)$ & 0.563 \\
Vomiting & $3(5.77)$ & $0(0.00)$ & 0.083 \\
Tachycardia & $6(11.54)$ & $5(9.43)$ & 0.763 \\
Liver injury & $12(23.08)$ & $9(16.98)$ & 0.512 \\
Total & $28(53.85)$ & $17(32.08)$ & 0.101 \\
\hline
\end{tabular}

$\mathrm{AE}$, adverse effect. P-value as determine by ${ }^{\mathrm{a}}$ Chi-square test. Significant $\mathrm{P}$-values are noted in bold print.

treated with Arbidol (32). To date, no data are available in the medical literature referring to chest CT in COVID-19 patients treated with DRV/r.

Adverse effects (AEs) affect treatment compliance, and some may even make it impossible for their administration. SARS-CoV-2 infection is responsible for multi-organ damage; therefore overlapping post-medication AEs are not desirable. Gastrointestinal manifestations, changes in renal function, hypersensitivity reactions, prolongation of the QT interval, blood dyscrasias are the most frequent AE of LPV/r administration in case of patients with COVID-19, cited in the medical literature (33). In the present study, diarrhea was more frequently reported in patients treated with LPV/r compared to DRV/r ( $42.31 \%$ vs. $11.32 \%)$, but the number of patients with AEs after antiviral treatment did not statistically significantly differ in the two groups (53.85\% vs. $32.08 \%)$. Both drugs were well tolerated, and it was not necessary to stop their administration due to AEs. The studies with DRV/r in COVID-19 patients do not report any notable AEs for the drug (15). Osborne et al, in a systematic benefit-risk assessment made on 143 papers in 2020, concluded that the benefit-risk profile of the LPV/r therapy for patients infected with SARS-CoV-2 is still not positive without other data (33).

In conclusion, although treatment with $\mathrm{LPV} / \mathrm{r}$ or $\mathrm{DRV} / \mathrm{r}$ is still recommended, due to the lack of therapeutic alternatives in SARS-CoV-2 infection, the effects of the two therapies are far from that which one could expect. Considering our experience, 
except for a few AEs that could be managed conservatively without interruption of administration, the treatment did not show notable AEs.

\section{Acknowledgements}

Not applicable.

\section{Funding}

No funding was received.

\section{Availability of data and materials}

All data are registered at the Municipal Hospital Oradea 'Gavril Curteanu', Oradea, Bihor County, Romania.

\section{Authors' contributions}

$\mathrm{NN}, \mathrm{AC}$, IH and DCNC collected, analyzed and interpreted the patient data. NN, SB, DMT, RM, TB, CCD, and FB made substantial contributions to the conception of the work and interpretation of the data; also, they drafted the manuscript and were major contributors in writing the manuscript. All authors read and approved the final manuscript to be published. All the authors agreed to be accountable for all aspects of the work in ensuring that questions related to the accuracy or integrity of any part of the work are appropriately investigated and resolved.

\section{Ethics approval and consent to participate}

All patients signed an informed consent at the time of admission to the hospital and before the start of the antiviral treatment. The study was approved by the Ethics Commission of Medicine and Pharmacy Faculty, University of Oradea (no. 5/09.21.2020) and followed the World Medical Association Code of Ethics (Declaration of Helsinki, 1967).

\section{Patient consent for publication}

Not applicable.

\section{Competing interests}

The authors declare that they have no competing interests.

\section{References}

1. Docea AO, Tsatsakis A, Albulescu D, Cristea O, Zlatian O, Vinceti M, Moschos SA, Tsoukalas D, Goumenou M, Drakoulis N, et al: A new threat from an old enemy: Re-emergence of coronavirus (Review). Int J Mol Med 45 1631-1643, 2020.

2. He W, Yi GY and Zhu Y: Estimation of the basic reproduction number, average incubation time, asymptomatic infection rate, and case fatality rate for COVID-19: Meta-analysis and sensitivity analysis. J Med Virol 92: 2543-2550, 2020.

3. Acuti Martellucci C, Flacco ME, Cappadona R, Bravi F, Mantovani L and Manzoli L: SARS-CoV-2 pandemic: An overview. Adv Biol Regul 77: 10073, 2020.

4. Verity R, Okell LC, Dorigatti I, Winskill P, Whittaker C, Imai N, Cuomo-Dannenburg G, Thompson H, Walker PGT, $\mathrm{Fu} \mathrm{H}$, et al: Estimates of the severity of coronavirus disease 2019: A model-based analysis. Lancet Infect Dis 20: 669-677, 2020 .
5. WHO: Middle East respiratory syndrome coronavirus (MERS-CoV) 2019. Available from: https://www.who.int/emergencies/mers-cov/en/. Accessed September 16, 2020.

6. WHO: Summary of probable SARS cases with onset of illness from 1 November 2002 to 31 July 2003 2019. Available from: https://www.who.int/csr/sars/country/table2003_09_23/en/. Accessed September 16, 2020.

7. Kabir MT, Uddin MS, Hossain MF, Abdulhakim JA, Alam MA, Ashraf GM, Bungau SG, Bin-Jumah MN, Abdel-Daim MM and Aleya L: nCOVID-19 pandemic: From molecular pathogenesis to potential investigational therapeutics. Front Cell Dev Biol 8: 616, 2020.

8. Gautret P, Lagier JC, Parola P, Hoang VT, Meddeb L, Mailhe M, Doudier B, Courjon J, Giordanengo V, Vieira VE, et al: Hydroxychloroquine and azithromycin as a treatment of COVID-19: Results of an open-label non-randomized clinical trial. Int J Antimicrob Agents 56: 105949, 2020.

9. Singh AK, Singh A, Shaikh A, Singh R and Misra A: Chloroquine and hydroxychloroquine in the treatment of COVID-19 with or without diabetes: A systematic search and a narrative review with a special reference to India and other developing countries. Diabetes Metab Syndr 14: 241-246, 2020.

10. Mahévas M, Tran VT, Roumier M, Chabrol A, Paule R, Guillaud C, Fois E, Lepeule R, Szwebel TA, Lescure FX, et al: Clinical efficacy of hydroxychloroquine in patients with covid-19 pneumonia who require oxygen: Observational comparative study using routine care data. BMJ 369: m1844, 2020.

11. Orkin C, DeJesus E, Khanlou H, Stoehr A, Supparatpinyo K, Lathouwers E, Lefebvre E, Opsomer M, Van de Casteele T and Tomaka F: Final 192-week efficacy and safety of once-daily darunavir/ritonavir compared with lopinavir/ritonavir in HIV-1-infected treatment-naïve patients in the ARTEMIS trial. HIV Med 14: 49-59, 2013.

12. U.S. National library of medicine: Clinical trials. Available from: https://clinicaltrials.gov/ct2/home. Accessed September 16, 2020.

13. Cao B, Wang Y, Wen D, Liu W, Wang J, Fan G, Ruan L, Song B, Cai Y, Wei M, et al: A trial of lopinavir-ritonavir in adults hospitalized with severe Covid-19. N Engl J Med 382: 1787-1799, 2020.

14. De Meyer S, Bojkova D, Cinatl J, Van Damme E, Buyck C, Van Loock M, Woodfall B and Ciesek S: Lack of antiviral activity of darunavir against SARS-CoV-2. Int J Infect Dis 97: 7-10, 2020.

15. Chen J, Xia L, Liu L, Xu Q, Ling Y, Huang D, Huang W, Song S, Xu S, Shen Y and Lu H: Antiviral activity and safety of darunavir/cobicistat for the treatment of COVID-19. Open Forum Infect Dis 7: ofaa241, 2020.

16. Beigel JH, Tomashek KM, Dodd LE, Mehta AK, Zingman BS, Kalil AC, Hohmann E, Chu HY, Luetkemeyer A, Kline S, et al: Remdesivir for the treatment of Covid-19-preliminary report. N Engl J Med 383: 1813-1826, 2020.

17. FDA: Fact sheet for health care providers emergency use authorization (EUA) of remdesivir (GS-5734 ${ }^{\mathrm{TM}}$ ) 2020. Available from: https://www.fda.gov/media/137566/download. Accessed September 16, 2020.

18. Negrut N, Nistor-Cseppento DC, Khan SA, Pantis C, MaghiarTA, Maghiar O, Aleya S, Rus M, Tit DM, Aleya L, et al: Clostridium difficile infection epidemiology over a period of 8 years-a single centre study. Sustainability 12: 4439, 2020.

19. Negrut N, Khan S, Bungau S, Zaha D, Anca C, Bratu O, Diaconu $\mathrm{C}$ and Ionita-Radu F: Diagnostic challenges in gastrointestinal infections. Rom J Mil Med 123: 83-90, 2020.

20. Codrean A, Dumitrascu DL, Codrean V, Tit DM, Bungau S, Aleya S, Rus M, Fratila O, Nistor-Cseppento DC, Aleya L and Negrut N: Epidemiology of human giardiasis in Romania: A 14 years survey. Sci Total Environ 705: 135784, 2020.

21. WHO:ClinicalmanagementofCOVID-19:Interimguidance 2020. Available from: https://www.who.int/publications/i/item/clinical-management-of-covid-19. Accessed September 26, 2020.

22. Behl T, Kaur I, Bungau S, Kumar A, Uddin MS, Kumar C, Pal G, Sahil, Shrivastava K, Zengin G and Arora S: The dual impact of ACE2 in COVID-19 and ironical actions in geriatrics and pediatrics with possible therapeutic solutions. Life Sci 257: 118075, 2020.

23. Rodriguez-Nava G, Yanez-Bello MA, Trelles-Garcia DP, Chung CW, Friedman HJ and Hines DW: Performance of the quick COVID-19 severity index and the Brescia-COVID respiratory severity scale in hospitalized patients with COVID-19 in a community hospital setting. Int J Infect Dis 102: 571-576, 2021. 
24. Dreher M, Kersten A, Bickenbach J, Balfanz P, Hartmann B, Cornelissen C, Daher A, Stöhr R, Kleines M, Lemmen SW, et al: The characteristics of 50 hospitalized COVID-19 patients with and without ARDS. Dtsch Arztebl Int 117: 271-278, 2020.

25. WHO: Laboratory testing for coronavirus disease (COVID-19) in suspected human cases: Interim guidance 2020. Available from: https://apps.who.int/iris/handle/10665/331501, Accessed September 16, 2020

26. FDA: Allplex ${ }^{\mathrm{TM}}$ 2019-nCoV Assay 2020. Available from: https://www.fda.gov/media/137178/download. Accessed September 16, 2020.

27. Li TZ, Cao ZH, Chen Y, Cai MT, Zhang LY, Xu H, Zhang JY, $\mathrm{Ma} \mathrm{CH}$, Liu Y, Gao LJ, et al: Duration of SARS-CoV-2 RNA shedding and factors associated with prolonged viral shedding in patients with COVID-19. J Med Virol 93: 506-512, 2020.

28. Zhou B, She J, Wang Y and Ma X: The duration of viral shedding of discharged patients with severe COVID-19. Clin Infect Dis 71: 2240-2242, 2020.
29. Shen C, Yue X, Wang J, Shi C and Li W: Nocturnal oxygen therapy as an option for early COVID-19. Int J Infect Dis 98: 176-179, 2020.

30. Calina D, Docea AO, Petrakis D, Egorov AM, Ishmukhametov AA, Gabibov AG, Shtilman MI, Kostoff R, Carvalho F, Vinceti M, et al: Towards effective COVID-19 vaccines: Updates, perspectives and challenges (Review). Int J Mol Med 46: 3-16, 2020.

31. Sánchez-Oro R, Torres Nuez J and Martínez-Sanz G: Radiological findings for diagnosis of SARS-CoV-2 pneumonia (COVID-19). Med Clin (Barc) 155: 36-40, 2020

32. Li Y, Xie Z, Lin W, Cai W, Wen C, Guan Y, Mo X, Wang J, Wang Y, Peng P, et al: Efficacy and safety of Lopinavir/Ritonavir or Arbidol in adult patients with mild/moderate COVID-19: An exploratory randomized controlled trial. Med (NY) 1: 105-113. e4, 2020.

33. Osborne V, Davies M, Lane S, Evans A, Denyer J, Dhanda S, Roy D and Shakir S: Lopinavir-ritonavir in the treatment of COVID-19: A dynamic systematic benefit-risk assessment. Drug Saf 43: 809-821, 2020 